\title{
National trend in congenital heart disease mortality in China during 2003 to 2010: A population-based study
}

\author{
Zhan $\mathrm{Hu}, \mathrm{MD}, \mathrm{PhD},{ }^{\mathrm{a}, \mathrm{b}}$ Xin Yuan, $\mathrm{MD}, \mathrm{PhD},{ }^{\mathrm{c}, \mathrm{d}}$ Keqin Rao, $\mathrm{MD}, \mathrm{PhD},{ }^{\mathrm{e}}$ Zhe Zheng, MD, PhD, ${ }^{\mathrm{c}, \mathrm{d}}$ and \\ Shengshou $\mathrm{Hu}, \mathrm{MD}, \mathrm{PhD}^{\mathrm{c}, \mathrm{d}}$
}

\begin{abstract}
Background: Previous studies suggest that mortality from congenital heart diseases (CHDs) is declining in the United States. But we do not know what the CHD mortality trend is in China, especially the rural versus urban patterns. Our study aimed to determine recent changes in death caused by CHD in China and describe CHD mortality in rural and urban Chinese populations.
\end{abstract}

\begin{abstract}
Methods: The data source was the China Ministry of Health 2003 to 2010 annual reports. Mortality was defined as death caused by CHD. Mortality rates for each year were calculated per 10,000,000 person-years. Poisson regression and descriptive analyses were conducted for overall trend and subgroup analysis was conducted by sex, age, and urban versus rural residency to understand potential disparities in mortality.
\end{abstract}

Results: From 2003 to 2010, the overall mortality rate increased from 141 per 10,000,000 person-years in 2003 to 229 per $10,000,000$ person-years in 2010 , a $62.4 \%$ relative increase. This represents a region-sex adjusted annual increase of $9 \%$ (incidence rate ratio, 1.09; 95\% confidence interval, 1.09-1.10). The increase in CHD mortality was not uniformly observed across age groups, urban versus rural residence, and sex. The relative increases were $65.3 \%, 212.2 \%$, and $131.7 \%$ for ages 1 to 10 years, 21 to 64 years, and 65 years or older groups, respectively. Urban areas had a relative increase of $154.5 \%$ versus $5.3 \%$ for rural areas. Females who lived in an urban environment had a relative increase of $313.5 \%$.

Conclusions: Our observation showed an obvious increasing trend of CHD mortality in China. What is more, the increase in CHD mortality was not uniformly observed across subgroups. Such information is needed for strategy-making procedures. (J Thorac Cardiovasc Surg 2014;148:596-602)

Supplemental material is available online.

Congenital heart disease (CHD) is the world's most common birth defect, affecting more than $1 \%$ of newborns. ${ }^{1}$ Nearly $30 \%$ to $50 \%$ of birth defect mortality is attributable to CHD. ${ }^{2-5}$ In China, a national survey

From the Surgery Department, ${ }^{\text {a }}$ Peking Union Medical College Hospital, Beijing, China; Department of Cardiac Surgery, ${ }^{\mathrm{b}}$ Peking University First Hospital, Beijing, China; Chinese National Center for Cardiovascular Diseases, ${ }^{\mathrm{c}}$ Beijing, China; Department of Surgery, ${ }^{\mathrm{d}}$ Center for Regenerative Medicine, Fuwai Hospital, Peking Union Medical College, Chinese Academy of Medical Sciences, Beijing, China; and National Center for Health Statistics, ${ }^{\text {e }}$ Ministry of Health of the People's Republic of China, Beijing, China.

This study was supported by the National Natural Science Foundation of China (grant No. 81270302), Peking Union Medical College Youth Fund (grant No. 2012-XHQN08), and the Fuwai Science and Technology Star Project (grant No. 2012-FWXX05).

Disclosures: Authors have nothing to disclose with regard to commercial support. X.Y. contributed equally to this work.

Received for publication March 30, 2013; revisions received July 30, 2013; accepted for publication Aug 22, 2013; available ahead of print Oct 28, 2013.

Address for reprints: Xin Yuan, MD, PhD, Department of Surgery, Center for Cardiovascular Regenerative Medicine, Fuwai Hospital, Peking Union Medical College, Chinese Academy of Medical Science, 167A Beilishi Rd, Xi Cheng District, Beijing 100037, People's Republic of China (E-mail: yuanxin1008@ yahoo.com)

$0022-5223 / \$ 36.00$

Copyright $($ C 2014 by The American Association for Thoracic Surgery

http://dx.doi.org/10.1016/j.jtcvs.2013.08.067 measuring birth defect prevalence in the Chinese population reported that CHD is among the top 3, with a prevalence of 7 to 8 cases per 1000 live births, ${ }^{6}$ translating into 100,000 to 150,000 new cases annually. However, in China, there is also a growing trend of children with CHD surviving to adulthood making the treatment and management of CHD in older children and adults a growing public health problem in China today.

As the world's largest developing country, China is still characterized by large rural-urban disparities in many areas of health care. ${ }^{7,8}$ China's accelerated rate of urbanization has further exacerbated these disparities. However, before our study there have been no reports available describing CHD mortality in the Chinese rural and urban populations, with the exception of several small-sized clinical series. Although it has been posited that urban-rural disparities exist in CHD mortality rates, our study is the first to use a comprehensive data sample to answer this question.

In our study, we used age, sex, and cause-specific mortality data from the largest and longest-running Chinese health registration system administered by the Chinese Ministry of Health. $^{9}$ This system samples about $10 \%$ of the Chinese population, amounting to 100 million residents, from different regions throughout China selected by the Chinese Ministry of Health. We used only the 2003-2010 mortality data because these data are coded in accordance with the 


\section{Abbreviations and Acronyms \\ $\mathrm{CHD}=$ congenital heart disease \\ ICD = International Classification of Diseases}

10th edition of the International Classification of Diseases (ICD-10). We then used these data to describe the temporal changes and rural-urban disparities in Chinese CHD mortality.

\section{MATERIALS AND METHODS}

Chinese Health Statistics, including multiple causes of death public-use data files, are released annually by the Health Statistics and Information Center, which is part of China's Ministry of Health. These files come from data collected from all death certificates issued for deaths occurring around China. The data files sample about $10 \%$ of the Chinese population, selected from affluent regions and surrounding suburban areas. In our study, we analyzed CHD mortality trend from 2003 to 2010. During this period, ICD-10 was used to identify mortality causes in the vital statistics, and up to 20 conditions were listed as contributing causes of death.

In our study, those with CHD listed as the underlying or contributing cause were considered as deaths resulting from CHD. The denominators for mortality rates were the national population estimates or census data (the year 2000) released from the National Bureau of Statistics of China (http://www.stats.gov.cn/tjsj/ndsj/). We used the national population information from the previous year as CHD mortality denominators. To account for the different age compositions among subpopulations, we adjusted the overall, rural- or urban-specific, and sex-specific mortality rate by applying the age-specific mortality rates to the population information of the previous year. For example, as for the CHD mortality of 2004, we used population estimates of 2003 as the denominators; also, we used the 2003 sex and age structures to adjust the CHD mortality of 2004. Annual age-specific CHD death rates were calculated per $10,000,000$ population among the following age groups: $<1$ year, 1 to 10 years, 11 to 20 years, 21 to 64 years, and $>65$ years, stratified by sex and rural/urban areas.

We assessed the trend in the mortality rates during the study period. We then fitted a generalized linear mixed effects model with a Poisson link function, adjusting for age-sex, annual gross domestic product, health care workers per 100,000 population, and physician-to-nurse ratio. The total person-years (at the log scale) was used as an offset in the model to obtain the expected numbers of deaths. The time (year) was modeled as an ordinal time variable, ranging from 0 to 7 , corresponding to years 2003 (Time $=0)$ to 2010 (Time $=7$ ), to represent the annual change in CHD-specific mortality. We estimated the risk-adjusted incidence rate ratio and its corresponding $95 \%$ confidence interval $[\mathrm{CI}]$ in each subsequent analysis.

All statistical testing was 2-sided, at a significance level of 0.05 , and all analyses were carried out using SAS version 9.3 64-bit version (SAS Institute Inc, Cary, NC). The authors had full access to and take full responsibility for the integrity of the data. The Fuwai Hospital Institutional Review Board reviewed and approved the study.

\section{RESULTS}

According to Chinese Health Statistics, deaths among Chinese citizens were steadily rising from 591.1 per 100,000 population in 2003 to 621.2 per 100,000 population in 2010. Death associated with CHD accounted for around $0.2 \%$ of total deaths in both years, overall CHD mortality increased by $62 \%$, from 141 to 229 per 10 million (Table 1 ).

\section{CHD Mortality by Areas and by Sex}

CHD mortality in urban areas increased significantly from 121 to 308 deaths per 10 million, but only moderate increases were observed in rural areas (Table 1 and Figure 1). Mortality increased among both male and female individuals, but the trend in females was larger, with an increase of $127 \%$ from 124 to 282 per 10 million (Table 1 and Figure 2). What is more, we saw an increasing mortality trend among urban females from 111.0 to 459.0 per 10 million and a decreasing trend from 131 to 127 per 10 million in rural females (Table 1).

\section{CHD Mortality by Age Groups}

We observed a reverse J-shaped pattern of age-specific mortality associated with CHD. Mortality was highest among infants and lowest among citizens older than age 65 years. The proportion of mortality among adults older than age 20 years changed from $21 \%$ in 2003 to $45 \%$ in 2010.

\section{Infant Mortality}

Infant mortality accounted for $41.2 \%$ of all mortalityassociated CHD. There was an increasing trend of overall infant mortality associated with CHD before 2007 and a slight drop since then. Throughout the study period, CHD-associated mortality in infants was 7585.5 per 10 million. Overall infant mortality was 5803.9 per 10 million, peaked to 7960.810 million in 2007, and dropped to 7470.6 10 million in 2010. After 2005, the urban population had a higher mortality associated with CHD in infants than the rural population (Figure 3, A). Furthermore, the adjusted age time interaction term was associated with higher mortality, indicating an increase of peak mortality age (Table 2).

\section{Child Mortality}

Among children aged 1 to 10 years, mortality associated with CHD increased $65.3 \%$ overall and $8.2 \%$ annually. Among the urban and rural populations, mortality associated with CHD increased $15.8 \%$ and $109.1 \%$, respectively (Figure 3, $B$ ).

Among children aged 11 to 20 years, mortality associated with CHD did not change significantly. Throughout the study period, mortality associated with CHD was higher among rural than among urban individuals in this population, except during 2003 and 2007 (Figure 3, C).

Overall, mortality among children who survived the first year of life accounted for $28.4 \%$ of all mortality associated with CHD.

\section{Adult Mortality}

Among adults aged 21 to 64 years, mortality associated with CHD increased by $212.2 \%$. This increase 
TABLE 1. Trend in congenital heart disease mortality in China, by year

\begin{tabular}{|c|c|c|c|c|c|c|c|c|}
\hline \multirow[b]{2}{*}{ Measure } & \multicolumn{8}{|c|}{ Year } \\
\hline & 2003 & 2004 & 2005 & 2006 & 2007 & 2008 & 2009 & 2010 \\
\hline \multicolumn{9}{|l|}{ Overall population } \\
\hline Population & $1,239,612,226$ & $1,283,604,890$ & $1,297,166,669$ & $1,305,781,632$ & $1,314,956,999$ & $1,320,825,559$ & $1,328,661,780$ & $1,333,782,508$ \\
\hline Deaths, ${ }^{*} \mathrm{n}$ & 17,424 & 19,269 & 16,092 & 19,272 & 24,916 & 21,105 & 22,292 & 30,520 \\
\hline $\begin{array}{l}\text { Mortality } \dagger \\
\quad(95 \% \mathrm{CI})\end{array}$ & $\begin{array}{c}141.0 \\
(138.5-142.7)\end{array}$ & $\begin{array}{c}150.0 \\
(148.0-152.3)\end{array}$ & $\begin{array}{c}124.0 \\
(122.2-126.0)\end{array}$ & $\begin{array}{c}148.0 \\
(145.5-149.7)\end{array}$ & $\begin{array}{c}189.0 \\
(187.1-191.9)\end{array}$ & $\begin{array}{c}160.0 \\
(157.6-162.0)\end{array}$ & $\begin{array}{c}168.0 \\
(165.6-170.0)\end{array}$ & $\begin{array}{c}229.0 \\
(226.3-231.4)\end{array}$ \\
\hline \multicolumn{9}{|l|}{ Females } \\
\hline Population & $599,336,257$ & $628,411,406$ & $637,573,500$ & $642,957,285$ & $648,691,289$ & $651,113,337$ & $654,095,826$ & $656,487,972$ \\
\hline Deaths, ${ }^{*} \mathrm{n}$ & 7416 & 8771 & 7357 & 8088 & 10,516 & 9209 & 9344 & 18,498 \\
\hline $\begin{array}{l}\text { Mortality } \dagger \\
\quad(95 \% \mathrm{CI})\end{array}$ & $\begin{array}{c}124.0 \\
(120.9-126.6)\end{array}$ & $\begin{array}{c}140.0 \\
(136.7-142.5)\end{array}$ & $\begin{array}{c}115.0 \\
(112.8-118.1)\end{array}$ & $\begin{array}{c}126.0 \\
(123.1-128.6)\end{array}$ & $\begin{array}{c}162.0 \\
(159.0-165.2)\end{array}$ & $\begin{array}{c}141.0 \\
(138.6-144.4)\end{array}$ & $\begin{array}{c}143.0 \\
(140.0-145.8)\end{array}$ & $\begin{array}{c}282.0 \\
(277.7-285.9)\end{array}$ \\
\hline \multicolumn{9}{|l|}{ Males } \\
\hline Population & $640,275,969$ & $655,193,484$ & $659,593,169$ & $662,824,347$ & $666,265,710$ & $669,712,222$ & $674,565,954$ & $677,294,536$ \\
\hline Deaths, ${ }^{*} \mathrm{n}$ & 10,008 & 10,497 & 8735 & 11,184 & 14,400 & 11,895 & 12,948 & 12,022 \\
\hline $\begin{array}{l}\text { Mortality } \dagger \\
\quad(95 \% \mathrm{CI})\end{array}$ & $\begin{array}{c}156.0 \\
(153.3-159.4)\end{array}$ & $\begin{array}{c}160.0 \\
(157.2-163.3)\end{array}$ & $\begin{array}{c}132.0 \\
(129.7-135.2)\end{array}$ & $\begin{array}{c}169.0 \\
(165.6-171.9)\end{array}$ & $\begin{array}{c}216.0 \\
(212.6-219.7)\end{array}$ & $\begin{array}{c}178.0 \\
(174.4-180.8)\end{array}$ & $\begin{array}{c}192.0 \\
(188.7-195.3)\end{array}$ & $\begin{array}{c}178.0 \\
(174.3-180.7)\end{array}$ \\
\hline \multicolumn{9}{|l|}{ Urban area } \\
\hline \multicolumn{9}{|c|}{ Overall population } \\
\hline Population & $455,770,983$ & $519,859,981$ & $542,215,668$ & $559,188,845$ & $577,266,123$ & $593,050,676$ & $607,198,434$ & $621,180,613$ \\
\hline Deaths, ${ }^{*} \mathrm{n}$ & 5514 & 8249 & 4654 & 8542 & 13,151 & 11,217 & 10,335 & 19,120 \\
\hline $\begin{array}{l}\text { Mortality } \dagger \\
\qquad(95 \% \mathrm{CI})\end{array}$ & $\begin{array}{c}121.0 \\
(117.8-124.2)\end{array}$ & $\begin{array}{c}159.0 \\
(155.3-162.1)\end{array}$ & $\begin{array}{c}86.0 \\
(83.4-88.3)\end{array}$ & $\begin{array}{c}153.0 \\
(149.5-156.0)\end{array}$ & $\begin{array}{c}228.0 \\
(223.9-231.7)\end{array}$ & $\begin{array}{c}189.0 \\
(185.7-192.7)\end{array}$ & $\begin{array}{c}170.0 \\
(166.9-173.5)\end{array}$ & $\begin{array}{c}308.0 \\
(303.5312 .2)\end{array}$ \\
\hline \multicolumn{9}{|l|}{ Urban area } \\
\hline \multicolumn{9}{|l|}{ Females } \\
\hline Population & $220,506,276$ & $254,506,620$ & $266,505,724$ & $275,352,847$ & $284,775,476$ & $292,349,888$ & $298,921,793$ & $305,923,396$ \\
\hline Deaths, ${ }^{*} \mathrm{n}$ & 2451 & 3823 & 1847 & 3630 & 5540 & 5236 & 4295 & 14,029 \\
\hline $\begin{array}{l}\text { Mortality } \dagger \\
\quad(95 \% \mathrm{CI})\end{array}$ & $\begin{array}{c}111.0 \\
(106.8-115.7)\end{array}$ & $\begin{array}{c}150.0 \\
(145.5-155.1)\end{array}$ & $\begin{array}{c}69.0 \\
(66.2-72.6)\end{array}$ & $\begin{array}{c}132.0 \\
(127.6-136.2)\end{array}$ & $\begin{array}{c}195.0 \\
(189.5-199.7)\end{array}$ & $\begin{array}{c}179.0 \\
(174.3-184.0)\end{array}$ & $\begin{array}{c}144.0 \\
(139.4-148.1)\end{array}$ & $\begin{array}{c}459.0 \\
(451.0-466.2)\end{array}$ \\
\hline \multicolumn{9}{|l|}{ Urban area } \\
\hline \multicolumn{9}{|l|}{ Males } \\
\hline Population & $235,264,707$ & $265,353,361$ & $275,709,944$ & $283,835,998$ & $292,490,647$ & $300,700,788$ & $308,276,641$ & $315,257,217$ \\
\hline Deaths, ${ }^{*} \mathrm{n}$ & 3063 & 4426 & 2806 & 4912 & 7611 & 5981 & 6040 & 5091 \\
\hline $\begin{array}{l}\text { Mortality } \dagger \\
\quad(95 \% \mathrm{CI})\end{array}$ & $\begin{array}{c}130.0 \\
(125.6-134.9)\end{array}$ & $\begin{array}{c}167.0 \\
(161.9-171.8)\end{array}$ & $\begin{array}{c}102.0 \\
(98.1-105.6)\end{array}$ & $\begin{array}{c}173.0 \\
(168.3-178.0)\end{array}$ & $\begin{array}{c}260.0 \\
(254.4-266.1)\end{array}$ & $\begin{array}{c}199.0 \\
(193.9-204.0)\end{array}$ & $\begin{array}{c}196.0 \\
(191.0-200.9)\end{array}$ & $\begin{array}{c}161.0 \\
(157.1-166.0)\end{array}$ \\
\hline \multicolumn{9}{|l|}{ Rural area } \\
\hline \multicolumn{9}{|c|}{ Overall population } \\
\hline Population & $783,841,243$ & $763,744,909$ & $754,951,001$ & $746,592,787$ & $737,690,876$ & $727,774,883$ & $721,463,346$ & $712,601,895$ \\
\hline Deaths, ${ }^{*} \mathrm{n}$ & 11,910 & 11,020 & 11,438 & 10,730 & 11,765 & 9888 & 11,957 & 11,400 \\
\hline $\begin{array}{l}\text { Mortality } \dagger \\
\quad(95 \% \mathrm{CI})\end{array}$ & $\begin{array}{c}152.0 \\
(149.2-154.7)\end{array}$ & $\begin{array}{c}144.0 \\
(141.6-147.0)\end{array}$ & $\begin{array}{c}152.0 \\
(148.8-154.3)\end{array}$ & $\begin{array}{c}144.0 \\
(141.0-146.5)\end{array}$ & $\begin{array}{c}159.0 \\
(156.6-162.4)\end{array}$ & $\begin{array}{c}136.0 \\
(133.2-138.6)\end{array}$ & $\begin{array}{c}166.0 \\
(162.8-168.7)\end{array}$ & $\begin{array}{c}160.0 \\
(157.1-163.0)\end{array}$ \\
\hline \multicolumn{9}{|l|}{ Rural area } \\
\hline \multicolumn{9}{|l|}{ Females } \\
\hline Population & $378,829,981$ & $373,904,786$ & $371,067,776$ & $367,604,438$ & $363,915,813$ & $358,763,449$ & $355,174,033$ & $350,564,576$ \\
\hline Deaths, ${ }^{*} \mathrm{n}$ & 4965 & 4948 & 5509 & 4458 & 4976 & 3973 & 5049 & 4469 \\
\hline $\begin{array}{l}\text { Mortality } \dagger \\
\qquad(95 \% \mathrm{CI})\end{array}$ & $\begin{array}{c}131.0 \\
(127.4-134.8)\end{array}$ & $\begin{array}{c}132.0 \\
(128.7-136.1)\end{array}$ & $\begin{array}{c}148.0 \\
(144.6-152.5)\end{array}$ & $\begin{array}{c}121.0 \\
(117.7-124.9)\end{array}$ & $\begin{array}{c}137.0 \\
(133.0-140.6)\end{array}$ & $\begin{array}{c}111.0 \\
(107.3-114.2)\end{array}$ & $\begin{array}{c}142.0 \\
(138.3-146.1)\end{array}$ & $\begin{array}{c}127.0 \\
(123.8-131.3)\end{array}$ \\
\hline \multicolumn{9}{|l|}{ Rural area } \\
\hline \multicolumn{9}{|l|}{ Males } \\
\hline Population & $405,011,262$ & $389,840,123$ & $383,883,225$ & $378,988,349$ & $373,775,063$ & $369,011,434$ & $366,289,313$ & $362,037,319$ \\
\hline Deaths, ${ }^{*} \mathrm{n}$ & 6945 & 6071 & 5929 & 6272 & 6789 & 5914 & 6908 & 6931 \\
\hline $\begin{array}{l}\text { Mortality } \dagger \\
\quad(95 \% \mathrm{CI})\end{array}$ & $\begin{array}{c}171.0 \\
(167.5-175.6)\end{array}$ & $\begin{array}{c}156.0 \\
(151.9-159.7)\end{array}$ & $\begin{array}{c}154.0 \\
(150.5-158.4)\end{array}$ & $\begin{array}{c}165.0 \\
(161.4-169.6)\end{array}$ & $\begin{array}{c}182.0 \\
(177.3-186.0)\end{array}$ & $\begin{array}{c}160.0 \\
(156.2-164.4)\end{array}$ & $\begin{array}{c}189.0 \\
(184.2-193.1)\end{array}$ & $\begin{array}{c}191.0 \\
(187.0-196.0)\end{array}$ \\
\hline
\end{tabular}

CI, Confidence interval. *Deaths due to congenital heart diseases. †Observed mortality from congenital heart diseases, represented in mortality per 10 million population. 


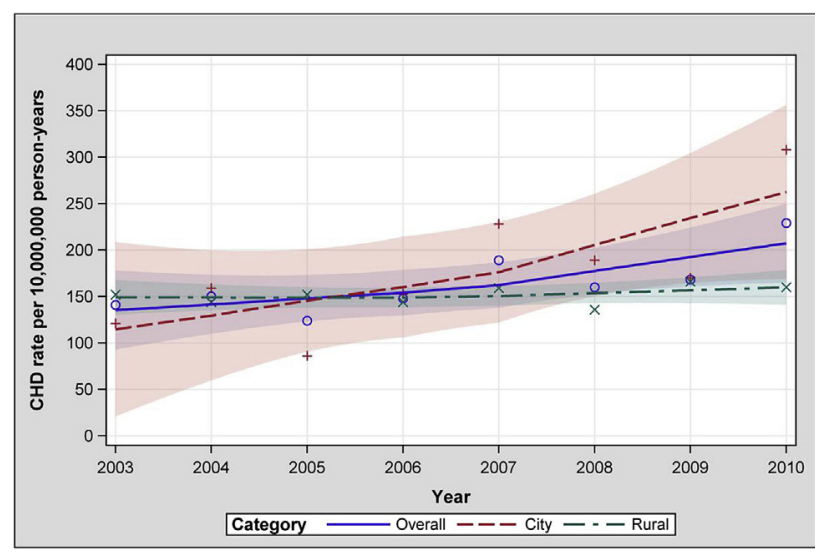

FIGURE 1. Observed trend in congenital heart disease $(C H D)$ mortality by city and rural residence from 2003 to 2010 (per 10,000,000 person-years) The red + symbols represent CHD mortality rate in urban areas each year. The green $\times$ symbols represent $\mathrm{CHD}$ mortality rate in rural areas each year. Blue circles represent the overall CHD mortality rate each year. The red dashed line represents regression curve of CHD mortality rate in urban areas, whereas the red shadow represents its $95 \%$ confidence interval. The green dashed line represents regression curve of $\mathrm{CHD}$ mortality rate in urban areas, and the green shadow represents its 95\% confidence interval. The blue solid line represents the regression curve of overall CHD mortality.

was driven by a significant rising mortality among urban population. CHD mortality among rural population remained stable throughout the study period (Figure 3, D).

Among adults aged $\geq 65$ years, we observed a rising trend of mortality associated with CHD over the study period. Again, the urban population mortality rate increased

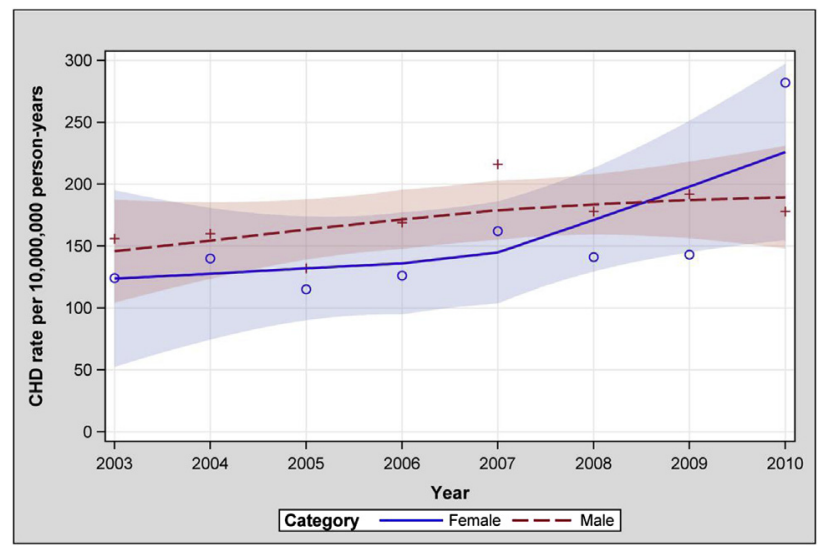

FIGURE 2. Observed trend in congenital heart disease (CHD) mortality by sex from 2003 to 2010 (per 10,000,000 person-years) The red + symbols represent CHD mortality rate among men each year. The blue circles represent CHD mortality rate among women each year. The red dashed line represents the regression curve of CHD mortality rate in urban areas, and the red shadow represents its $95 \%$ confidence interval. The blue solid line represents the regression curve of overall CHD mortality, and the blue shadow represents its $95 \%$ confidence interval. dramatically, and accounted for much of the overall increase. (Figure 3,E).

\section{Trends After Adjustment}

After adjusting for demographic and economic variables, time was still associated with increasing mortality (odds ratio [OR], 1.09; 95\% CI, 1.08-1.10). After adjustment, being a female, increased age, and living in a city were associated with low mortalities (Table 3).

Additionally, mortality in urban areas increased over time (city-time interaction, OR, 1.15; 95\% CI, 1.14-1.15). Overall mortality in females decreased over time (female-time interaction: OR, 0.99; 95\% CI, 0.99-0.99), but mortality in urban females increased from 2003 to 2010 (Table 2). The age-time interaction term was associated with higher mortality (OR, 1.04; 95\% CI, 1.04-1.05), indicating a slight increase in age of death.

\section{DISCUSSION}

A knowledge of a country's mortality patterns is essential to understand a country's public health needs and properly implement public health programs. However, China's CHD monitoring system is incomplete, making it difficult to document temporal changes in mortality rates. Moreover, China's rapid urbanization during the past few decades ${ }^{10}$ has widened the rural-urban gap and heavily influenced many health outcomes. Yet, before our study no data had been available to describe rural/urban disparities in CHD mortality rates.

Our study, which analyzed data from the largest and longest running Chinese health registration system, is the first to depict the temporal trend and the rural-urban disparities of Chinese CHD mortality. It could also offer an interesting platform in exploring health equity and access to health care in a developing country. In our study we found that the rate of change of CHD mortality in urban areas, when compared with those in rural areas, significantly increased over time; although most CHDrelated deaths still occur when a patient is aged $<1$ year, this pattern has changed between 2003 and 2010; and CHD mortality rates of females living in urban areas have increased significantly over time, whereas CHD mortality rates of females living in rural areas have slightly decreased.

Previous reports have shown that there has been a decline in CHD mortality in the American, English, and Canadian populations during the past 3 decades. ${ }^{1-14}$ However, in our study, we observed an increasing trend of $\mathrm{CHD}$ mortality in the Chinese population. There are several potential reasons for this trend. Compared with developed countries, patients with CHD in China have relatively limited access to diagnosis and treatment. However, treatment has improved in recent years. After implementing a fetal echocardiography training program, a rising $\mathrm{CHD}$ detection rate was observed in a 


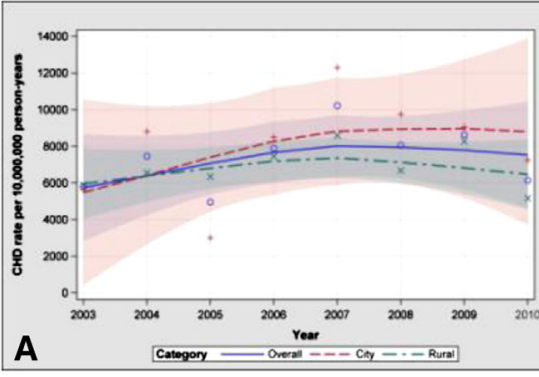

$<1$ year old

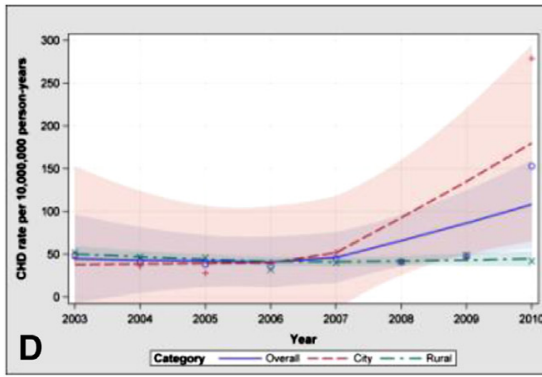

21-64 years old

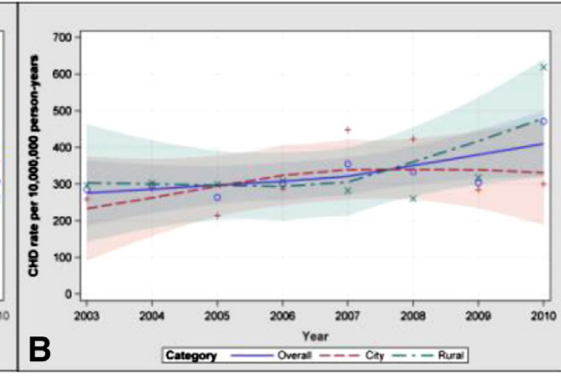

$1-10$ years old

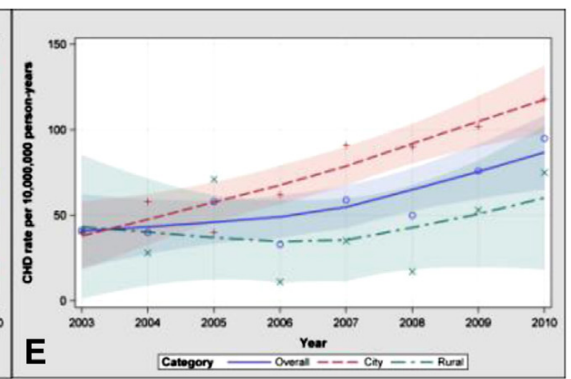

$\geqslant 65$ years old

FIGURE 3. Observed trend in congenital heart disease mortality by different age intervals (A, <1 year old; B, 1-10 years old; C, 11-20 years old; D, 21-64 years old; D, $\geq 65$ years old) from 2003 to 2010 (per 10,000,000 person-years). The red + symbol represents congenital heart disease (CHD) mortality rate in urban areas each year. The green $\times$ symbol represents CHD mortality rate in rural areas each year. The blue circles represent the overall CHD mortality rate each year. The red dashed line represents regression curve of CHD mortality rate in urban areas, and the red shadow represents its $95 \%$ confidence interval. The green dashed line represents the regression curve of CHD mortality rate in urban areas, and the green shadow represents its $95 \%$ confidence interval. The blue solid line represents the regression curve of overall CHD mortality, and the blue shadow represents its $95 \%$ confidence interval.

Chinese hospital, contributing to an increasing trend of CHD incidence at birth and therapeutic termination of pregnancy. ${ }^{15}$ Nationwide, a hospital-based birth defect monitoring system in China reports that the prevalence of CHD almost quintupled between 1996 and 2009. ${ }^{16}$ And there is substantially similar pattern of CHD subsets between China and North America. ${ }^{17,18}$ The increasing prevalence of $\mathrm{CHD}$ at birth could partly explain the growing trend of CHD mortality. What is more, a rising

TABLE 2. Affect of time interaction on mortality in China

\begin{tabular}{lcc}
\hline Outcomes & $\begin{array}{c}\text { Odds ratio over } \\
\text { trend of time }\end{array}$ & $\mathbf{9 5 \%}$ Confidence interval \\
\hline Unadjusted & & \\
Females & 1.00 & $0.99-1.01$ \\
Urban & 1.04 & $1.04-1.05$ \\
Age* & 1.03 & $1.03-1.04$ \\
Urban & 1.10 & $1.10-1.11$ \\
Adjusted $\dagger$ & & \\
Females & 0.99 & $0.99-0.99$ \\
Urban & 1.15 & $1.14-1.15$ \\
Age* & 1.04 & $1.04-1.05$ \\
Urban & 1.09 & $1.09-1.10$ \\
\hline
\end{tabular}

*In 5-year age group. $\dagger$ Adjusted for age and sex, annual gross domestic product, health care workers per 100,000 population, and physician-to-nurse ratio.
CHD detection rate could not only be observed in infants and children but also in adults due to the improved access to medical care during the study period, especially for those with relatively mild congenital heart malformation

TABLE 3. Affect of city or rural residence, sex, age, and time on mortality in China

\begin{tabular}{lcc}
\hline \multicolumn{1}{c}{ Outcomes } & Odds ratio & $\mathbf{9 5} \%$ Confidence interval \\
\hline $\begin{array}{l}\text { Unadjusted } \\
\text { Demographic }\end{array}$ & & \\
$\quad$ Female & 0.99 & $0.99,1.01$ \\
$\quad$ Age* & 0.62 & $0.62,0.62$ \\
Geographic & & \\
$\quad$ Urban & 1.20 & $1.18,1.21$ \\
$\quad$ Trend over time & & \\
$\quad$ Annual change & 1.09 & $1.08,1.09$ \\
Adjusted $\dagger$ & & \\
Demographic & & $0.90,0.91$ \\
$\quad$ Female & 0.90 & $0.67,0.67$ \\
$\quad$ Age* & 0.67 & $0.90,0.92$ \\
Geographic & & \\
$\quad$ Urban & & $1.08,1.10$ \\
Trend over time & 0.91 & \\
$\quad$ Annual change & 1.09 & \\
\hline
\end{tabular}

*In 5-year age group. †Adjusted for age and sex, annual gross domestic product, health care workers per 100,000 population, and physician-to-nurse ratio. 
who can survive into adulthood without intervention. The growing CHD detection rate may contribute to a significant increase of CHD mortality. However, this may reflect a fake increase in mortality, reflecting instead a real increase in diagnostic rate. Although reported deaths certainly seem to be increasing, there is not sufficient evidence to show that the prognosis of diagnosed CHD is deteriorating in China.

The observed CHD mortality rate in urban areas increased significantly faster than the rate in rural areas, almost tripling from 121 per 10 million person-years in 2003 to 309 per 10 million person-years in 2010 . One possible explanation is the dramatic differences in access to health care resources in urban and rural areas. ${ }^{19}$ Previous studies have demonstrated that different payer status influences access to health care resources among patients with CHD. In the United States, a study analyzing 9656 Medicaid patients ${ }^{20}$ found that Medicaid patients have a higher risk of death compared with commercial insurance or managed care patients. In China, rapid urbanization intensifies inequalities of access to health care, both between rural and urban areas ${ }^{19}$ and within urban areas. ${ }^{21}$ Because of accelerated economic growth and a 1984 decision to broaden the criteria for what constitutes a "city" or "town," 22 large numbers of surplus agricultural workers have continuously migrated into urban areas and become classified as urban residents. However, although officially urbanized, the majority of these workers have a low socioeconomic status and have limited access to health care. As a result, this growing proportion of the migrant population may have contributed to the CHD mortality increase in urban areas. Previously, we explained the rise in CHD mortality in the general Chinese population by improvement in CHD detection rates. The CHD detection rates may increase more obviously in urban areas due to better health care resources, thus explaining the rapid increase of CHD mortality in urban areas.

In our study, the observed city mortality was lower than rural rates at the beginning of the century but surpassed rural rates during 2005, whereas after adjustment city residence was significantly associated with a lower CHD mortality rate, which is consistent with results from the Congenital Corvitia study in The Netherlands. ${ }^{23}$ This finding may reflect the overall advantages of the health care delivery system in urbanized areas compared with those in rural areas. Urbanization has deeply affected China's health care delivery system. ${ }^{24}$ To some degree, urbanization improves health care quality, especially for cardiovascular diseases. ${ }^{25}$ The treatment of CHD is a specialized area of cardiology requiring specific expertise. Previous studies demonstrated that better CHD treatment outcomes occurred in hospitals with expertise in CHD treatment and high volume ${ }^{26,27}$ conditions that occur more frequently in urban areas. Differing rates of CHD mortality has also been observed in different socioeconomic groups, and in groups with different access to medical care.

Consistent with previous reports among other populations, ${ }^{12}$ our study showed that a larger proportion of CHD deaths now occur in adults. Although children have the highest CHD mortality rate, we observed slight mortality declines in this group. This trend is mainly driven by children younger than age 1 year and children between ages 10 and 20 years. The Tomorrow Program, developed by the Chinese government to improve health care access for poor families, has improved specialty $\operatorname{care}^{28}$ and increased public awareness and support for children with CHD, which may have contributed to the mortality decline among children within Chinese society. In our study, we found that mortality occurred earlier among Chinese rural citizens, with mortality rising in the age 1 to 10 years age interval but declining among all other age groups. However, among Chinese urban citizens a rising mortality trend was observed throughout adulthood. Attention should be drawn to changing mortality rates in specific age groups to build efficient health services targeting these populations in the future.

We found that the CHD mortality rate among urban women also increased significantly over time. The improvement of CHD detection rate may be 1 reason because women tended to have less access to medical care in the past. By the end of 2010, the female population in urban areas was reported to be 0.7 billion, accounting for some $48.7 \%$ of the total Chinese population. ${ }^{10}$ Because the number of urban women has increased dramatically during the past couple of decades, if the CHD occurrence rate and sex ratio among CHD patients remains unchanged, the increasing CHD mortality rate will lead to a growing rate of absolute CHD mortality among women in the future. This trend will deeply influence the absolute numbers and sex distribution of patients with CHD.

Our results may provide policy makers in Chinese public health departments with first-hand material. Because city dwelling is associated with lower CHD mortality according to our results, outreach to rural areas should be enhanced. And all females living in urban areas should have regular screening to slow the rise we observed.

This research has several limitations: first, although a death certificate signed by a physician is required by law to report and record any cause of death, China does not have a complete nationwide death registration system. As a result, we could only obtain data from Chinese Health Statistics, which measures approximately $10 \%$ of the population from selected urban and rural areas. In these data, large cities and surrounding areas were more likely to be included in the registry; thus, the data are not representative of the general population in China. However, after comparing the total death rate between the death registry data and national census data, we found that the 
mortality trends matched well in the whole population and throughout subgroups (ie, urban males, urban females, rural males, and rural females; see Figure E1). Actually, the system does provides data from $>100$ million residents in areas with relatively good reporting and classification mechanisms, which helps ensure data quality. Second, we did not look at the CHD mortality trend before 2003 because the death coding system changed from ICD 9 to ICD 10 in 2002. Without data before 2003, we cannot measure long-term mortality trends. Third, CHD is a big diagnosis group, including various disease subtypes. However, due to lack of data, we could neither provide a breakdown of the frequency of each disease subtype nor provide the mortality trend of each major subtype. More precise studies will rely on a more comprehensive and representative surveillance system; however, our study was as precise as possible using the data available. Third, the definition of urban and rural varies over different nations. Our conclusions on urban/rural disparity in a Chinese population may not apply to foreign populations. But this is the only geographic information available from our data.

\section{CONCLUSIONS}

In our study, we examined the CHD mortality trend in China during the past 8 years, with a particular emphasis on the urban-rural disparities in CHD prevalence and mortality. We found that the overall CHD mortality rate in cities, compared with rural areas, increased significantly from 2003 to 2010 . The mortality rate among urban-dwelling females has also increased significantly. The average age of death from CHD has increased during this same period of time, possibly driven by improvements in health care quality. Although our study has several limitations, it is the largest study focusing on CHD mortality in a large population-based Chinese sample using a comprehensively validated risk adjustment tool. Such information is needed as a basis for working out and evaluating interventions and for the ongoing monitoring of CHD mortality and allocation of health care resources to properly treat patients with CHD.

The authors thank Dr Yun Wang from the Harvard School of Public Health and the Center for Outcomes Research and Evaluation, Yale-New Haven Hospital and Yale University, for providing valuable comments on the statistical analysis.

\section{References}

1. Marelli AJ, Mackie AS, Ionescu-Ittu R, Rahme E, Pilote L. Congenital heart disease in the general population: changing prevalence and age distribution. Circulation. 2007;115:163-72.

2. Petrini J, Damus K, Johnston RB Jr. An overview of infant mortality and birth defects in the united states. Teratology. 1997;56:8-10.

3. Yang Q, Khoury MJ, Mannino D. Trends and patterns of mortality associated with birth defects and genetic diseases in the united states, 1979-1992: an analysis of multiple-cause mortality data. Genetic Epidemiol. 1997; 14:493-505.
4. Petrini J, Damus K, Russell R, Poschman K, Davidoff MJ, Mattison D. Contribution of birth defects to infant mortality in the united states. Teratology. 2002;66(Suppl 1):S3-6.

5. Yang Q, Chen H, Correa A, Devine O, Mathews TJ, Honein MA. Racial differences in infant mortality attributable to birth defects in the United States, 1989-2002. Birth Defects Res. 2006;76:706-13.

6. National Center for Cardiovascular Disease. Chinese Cardiovascular disease report 2005. Beijing: Encyclopedia of China Publishing House, 2006: 103-5.

7. Dong X, Simon MA. Health and aging in a Chinese population: urban and rural disparities. Geriatr Gerontol Int. 2010;10:85-93.

8. Fang H, Chen J, Rizzo JA. Explaining urban-rural health disparities in China. Med Care. 2009;47:1209-16.

9. Health Statistics and Information Center, Ministry of Health of People's Republic of China. Vital statistics annual report, Beijing [in Chinese]. Beijing: Health Statistics and Information Center, the Ministry of Health of People's Republic of China; 2010.

10. National Bureau of Statistics of China. Chinese statistical yearbook, Beijing [in Chinese]. Beijing: National Bureau of Statistics of People's Republic of China; 2011.

11. Health Canada. Congenital anomalies in Canada-a perinatal health report, 2002. Ottawa: Minister of Public Works and Government Services Canada, 2002:15-9.

12. Boneva RS, Botto LD, Moore CA, Yang Q, Correa A, Erickson JD. Mortality associated with congenital heart defects in the United States: trends and racial disparities, 1979-1997. Circulation. 2001;103:2376-81.

13. Gilboa SM, Salemi JL, Nembhard WN, Fixler DE, Correa A. Mortality resulting from congenital heart disease among children and adults in the united states, 1999 to 2006. Circulation. 2010;122:2254-63.

14. Billett J, Majeed A, Gatzoulis M, Cowie M. Trends in hospital admissions, in-hospital case fatality and population mortality from congenital heart disease in england, 1994 to 2004. Heart. 2008;94:342-8.

15. Yu Z, Xi Y, Ding W, Han S, Cao L, Zhu C, et al. Congenital heart disease in a chinese hospital: pre- and postnatal detection, incidence, clinical characteristics and outcomes. Pediatr Int. 2011;53:1059-65.

16. Dai L, Zhu J, Liang J, Wang YP, Wang H, Mao M. Birth defects surveillance in china. World J Pediatr. 2011;7:302-10.

17. van der Linde D, Konings EEM, Slager MA, Witsenburg M, Helbing WA, Takkenberg JJM, et al. Birth prevalence of congenital heart disease worldwide: a systematic review and meta-analysis. J Am Coll Cardiol. 2011; $58: 2241$.

18. Yang XY, Li XF, Lü XD, Liu YL. Incidence of congenital heart disease in Beijing, China. Chin Med J. 2009;122:1128-32.

19. Joshi R, Jan S, Wu Y, MacMahon S. Global inequalities in access to cardiovascular health care: our greatest challenge. J Am Coll Cardiol. 2008;52: 1817-25.

20. DeMone J, Gonzalez P, Gauvreau K, Piercey G, Jenkins K. Risk of death for medicaid recipients undergoing congenital heart surgery. Pediatr Cardiol. 2003;24:97-102.

21. Luo J, Zhang X, Jin C, Wang D. Inequality of access to health care among the urban elderly in northwestern china. Health Pol. 2009;93:111-7.

22. Ministry of Civil Affairs of the People's Republic of China. Ratified by the State Council: Modified criteria for classifying towns, Nov 22, 1984 [in Chinese]. Available at: http://qhs.Mca.Gov.Cn/article/zcwj/qhg1/200711/ 20071100004361.shtml. Accessed September 27, 2013.

23. Zomer AC, Vaartjes I, Uiterwaal CS, van der Velde ET, van den Merkhof LF, Baur LH, et al. Circumstances of death in adult congenital heart disease. Int J Cardiol. 2012;154:168-72.

24. Rossi-Espagnet A. Primary health care in the context of rapid urbanization. Commun Dev J. 1983;18:104.

25. Suarez-Varela MM, Llopis Gonzalez A, Tejerizo Perez ML. Variations in avoidable mortality in relation to health care resources and urbanization level. J Environ Pathol Toxicol Oncol. 1996;15:149-54.

26. Jenkins KJ, Newburger JW, Lock JE, Davis RB, Coffman GA, Iezzoni LI In-hospital mortality for surgical repair of congenital heart defects: preliminary observations of variation by hospital caseload. Pediatrics. 1995;95:323-30.

27. Karamlou T, Diggs BS, Person T, Ungerleider RM, Welke KF. National practice patterns for management of adult congenital heart disease. Circulation. 2008; 118:2345-52.

28. Ding W. Status of paediatric cardiac surgery in china. Heart Lung Circ. 2001;10: A16-9. 

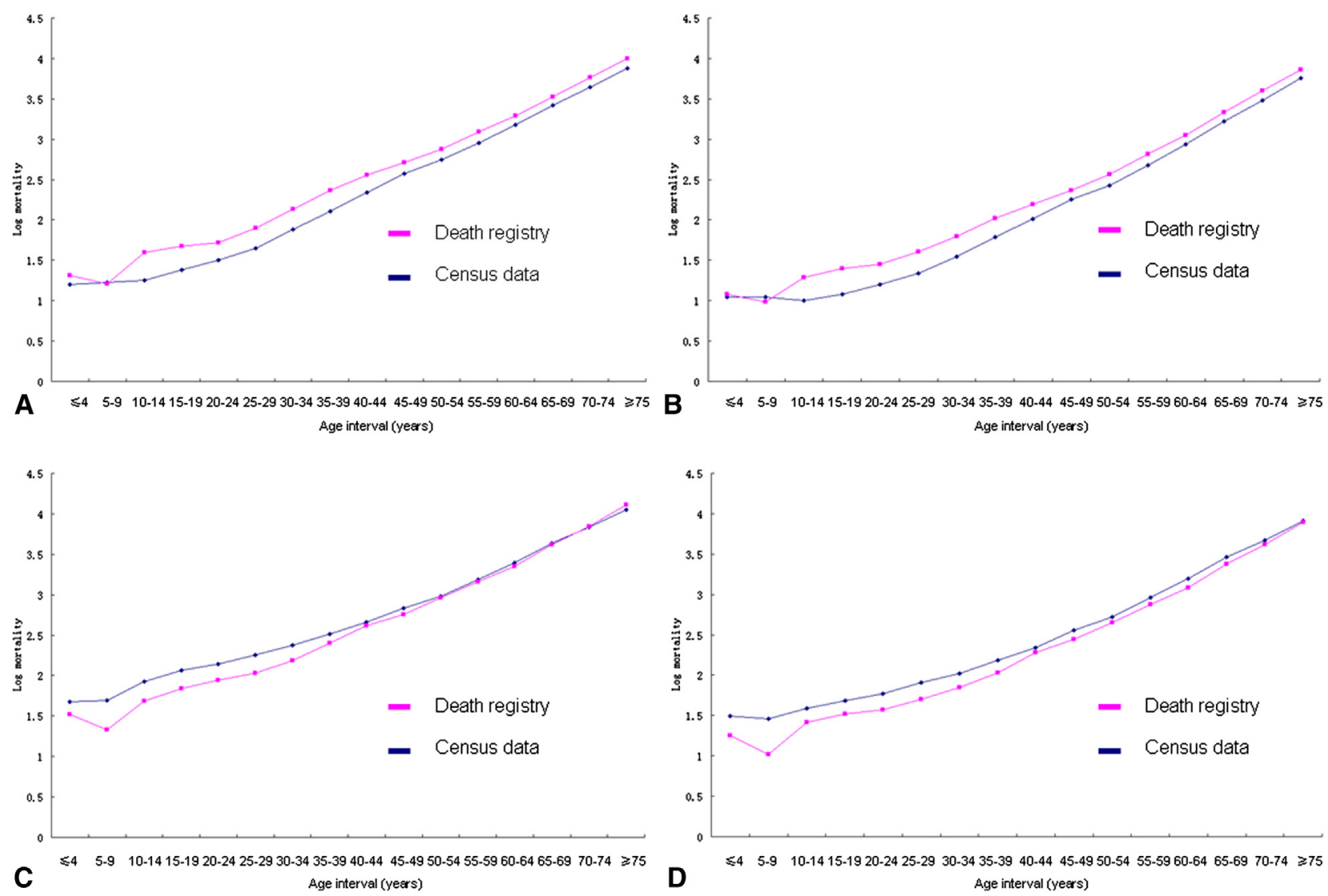

FIGURE E1. All-cause mortality in a Chinese population. Comparison between death registry and population census. A, Urban males. B, Urban females. C, Rural males. D, Rural females. 